\title{
Sixteen years age limit for learner drivers in Sweden - an evaluation of safety effects
}

Reprint from Accident Analysis \& Prevention 32 (2000),

$$
\text { pp. 25-35 }
$$

Nils Petter Gregersen, Hans-Yngve Berg, Inger Engström,

Sixten Nolén, Anders Nyberg, VTI and

Per-Arne Rimmö, University of Uppsala

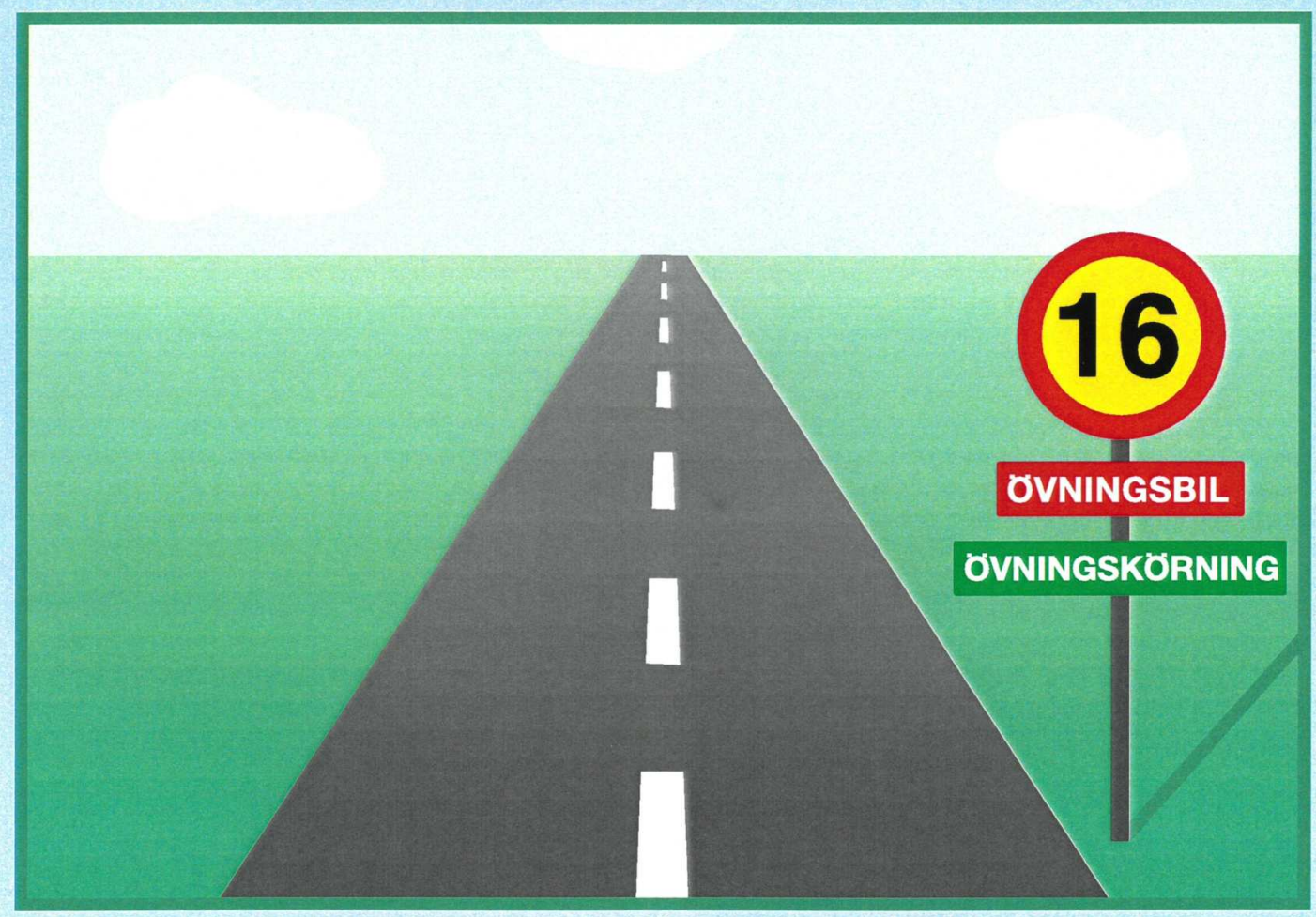


VTI särtryck 334 - 1999

\section{Sixteen years age limit for learner drivers in Sweden - an evaluation of safety effects}

Reprint from Accident Analysis \& Prevention 32 (2000), pp. 25-35

Nils Petter Gregersen, Hans-Yngve Berg, Inger Engström, Sixten Nolén, Anders Nyberg, VTI and Per-Arne Rimmö, University of Uppsala 


\title{
Sixteen years age limit for learner drivers in Sweden-an evaluation of safety effects
}

\author{
Nils P. Gregersen ${ }^{a, b, *}$, Hans-Yngve Berg a,b ${ }^{a}$ Inger Engström ${ }^{a, c}$, Sixten Nolén ${ }^{a, b}$, \\ Anders Nyberg a,d, Per-Arne Rimmö ${ }^{\mathrm{e}}$ \\ a Swedish National Road and Transport Research Institute (VTI), Linköping, Linköping, Sweden \\ ${ }^{\mathrm{b}}$ Department of Health and Environment, University of Linköping, Linköping, Sweden \\ ${ }^{c}$ Department of Education and Psychology, University of Linköping, Linköping, Sweden \\ ${ }^{\mathrm{d}}$ Department of Education, University of Uppsala, Uppsala, Sweden \\ e Department of Psychology, University of Uppsala, Uppsala, Sweden
}

Received 17 October 1997; received in revised form 4 March 1999; accepted 24 March 1999

\begin{abstract}
Through a reform implemented in Sweden, September 1993, the age limit for practising car driving was lowered from $17 \frac{1}{2}$ to 16 years while the licensing age remained 18 . The purpose of lowering the age limit was to give the learner drivers an opportunity to acquire more experience as drivers before being allowed to drive on their own. The primary aim of this study was to evaluate the effect of the reform in terms of accident involvement and data were therefore obtained from the national register of police reported accidents. The results show that after the reform there was a general reduction in the accident risk (accidents per 10 million $\mathrm{km}$ ) of novice drivers with approximately $15 \%$. Additional analyses show that the reduction of accident risk in the group who utilised the new age limit was approximately $40 \%$, whereas those who did not utilise the prolonged training period did not benefit at all. Between 45 and $50 \%$ of the age population were found to utilise the reform. The accident reduction does not seem to be just an initial first year effect since the results were similar over 3 years of novice drivers during their first 2 years with a licence. These results suggest that the reform has been beneficial for the safety of novice drivers in Sweden. The results also suggest a potential for additional safety improvements if more young learner drivers can be brought to utilise the low age limit. (C) 1999 Elsevier Science Ltd. All rights reserved.
\end{abstract}

Keywords: Learner drivers; Accident involvement; Safety effects; Sixteen years old

\section{Introduction}

Through a reform implemented in September 1993, the age limit for practising car driving was lowered from $17 \frac{1}{2}$ to 16 years while the licensing age remained 18. The purpose of lowering the age limit was to give the learner drivers an opportunity to acquire more experience as drivers before being allowed to drive on their own.

A large number of studies have drawn attention to the fact that one of the largest contributory factor to novice drivers' crash involvement is their lack of experi-

\footnotetext{
*Corresponding author. Tel.: +46-13-204000; fax: +46-13141436.

E-mail address: nils.petter.gregersen@vti.se (N.P. Gregersen)
}

ence (Pelz and Schuman, 1971; Spolander, 1983; Maycock et al., 1991; Levy, 1990; Cooper et al., 1995). During the last decade numerous literature reviews on young, novice drivers and driver training have been published. In all these reviews the lack of experience has been pointed out as a serious problem (Drummond et al., 1993; Smith, 1994; Lynam and Twisk, 1995; Cavallo and Triggs, 1996; Gregersen, 1996a; Mayhew and Simpson, 1996).

A common model for explaining why experience lowers the accident risk is that new drivers go through several phases of behavioural control in which they learn to handle the large number of assignments which are included in driving a car. The new driver is faced with many new tasks and situations, all of which require mental resources. The perceptual situation is new 
and imposes special requirements on visual search skills, and interpretation of what is happening in the surrounding environment. The handling of the car itself also requires a certain mental capacity involving a number of control levers, stalks and warning devices which must be used and co-ordinated in a complex pattern. The entire traffic environment with all its rules, regulations and requirements for specific behaviour also increases the mental workload. With increasing experience, however, more and more of these tasks will become automated and the mental workload will reduce.

According to Rasmussen (1984) the skill acquisition process and the behavioural control can be described at three levels. At the first level of behaviour control, the knowledge based level, extensive mental effort is allocated to attention, decision making and acting; as in the case of identifying the need for gear shifting, decision on how to perform the different tasks that are involved and the actual combination and performance of the task. Through experience the solution of the task becomes familiar and mental rules are developed. This is according to Rasmussen the rule based level. These rules can combine several steps of different solutions or nested subtasks so that the driver will gain control over long behaviour sequences. For example, in gear shifting the whole sequence will be solved as one single task and the effort demanding fragmentation will be avoided. With yet further experience combined action chains will be more automatically controlled. Attention is then needed rather to decide when to shift gear, than how to do it. This development towards the skill based level, makes it possible to shift more of the attention and decision making from the primary driving task to the driving environment, other road users etc. and makes it possible to predict the behaviour of other road users and evaluate hazards in traffic.

This knowledge about the process of experience gaining and its potential safety benefits was one of the main arguments behind the decision to lower the age limit for practising in Sweden from $17 \frac{1}{2}$ to 16 years. By keeping the licensing age at 18 years, this made it possible to gain 2 years of experience under mandatory supervision before driving alone.

During the first 5 years after the introduction of the new age limit, the Swedish system offered two possibilities with slightly different regulations. At an early start

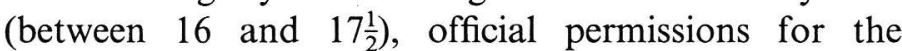
learner, and for a supervisor, were required, whereas at a later start (after $17 \frac{1}{2}$ ) only the learner permit was needed. In October 1998 the supervisor's permit became obligatory for all ages. Currently all learner drivers must have a learner's permit and a supervisor's permit if a lay instructor such as a parent is engaged. If only professional driving schools are used, no supervisor's permit is required. A supervisor must always be at least
24 years old and must have had a driving licence continuously for the past 5 years without it having been recalled by the authorities. For all learner drivers the choice is free to go through the education and training in a driving school and/or together with a lay supervisor. Skid training, which is lasting for about half a day is compulsory for all learner drivers in Sweden.

Several countries have introduced different systems aiming at increased experience. Mainly, two different types of systems have been used: an extended learning period and, graduated licensing. The general idea behind extending the learner-driving period in Sweden, Norway, France, Belgium and other countries is to increase the total bank of experience under supervision. One of the main assumptions has been that a learner driver with extended practice before receiving a driving licence will be better off to utilise the mental resources required and thus become a safer driver. During such a prolonged period, the learner driver will have more time to acquire knowledge and experience how to handle the car and to increase automation of action and reaction. More training will also increase actual experience in handling various traffic situations and thus learning to interact with other road users in everyday traffic situations. Learning from formal rules and behavioural patterns is one thing, but learning to drive in smooth interaction with other road users is often something quite different. Along with the adaptation towards an informal behavioural pattern the learner driver will have opportunities to experience that the behaviour of other road users is not always entirely predictable. This process develops gradually over a period of time, under which safety motives are balanced against other goals such as smoothness and transportation needs. However, proponents of formal traffic education have expressed their concern about problems connected with a non-professional driving education: Unless in an education situation proper, bad habits can be acquired quickly. Since research has shown the significance of experience in accident development it may be assumed that the total effect of experience is good for safety.

A Norwegian study (Moe, 1992) monitored the progress of 28 learner drivers who were given the opportunity to begin driving tuition from the age of 16 . The minimum age limit for issuing a driving licence was 18 years. Their evaluation of the training programme, including many obligatory sections, showed that it was mainly positive although the learners did not fully exploit the opportunity to practice driving as much as they could. The main reason referred to was a lack of time.

In evaluations of the French system contradictory results have been presented. Initially, a 70\% reduction of accidents were mentioned (Fafet, 1990). It turned out that there was no scientific support for these results and 
subsequently another evaluation study was carried out by Page (1995). He found a 30\% mean increase of accident-free distance driven as a result of the new system.

One precondition for a reduced age limit to have the expected effect is that it is really exploited to gain a lot of driving practice. Experience from France shows that the system reaches out to a relatively small group of youngsters. In the French system, a large portion of the training is obligatory, which is assumed to explain why many youngsters decline.

The evaluation of the Swedish reform comprises several sub-studies. Some of these are still running whereas others have been published elsewhere (Gregersen, 1996b, 1997). In these previously published parts of the evaluation the results of a 1-year after licence follow-up of accident involvement among the first learner drivers and a process evaluation have been presented. In the evaluation after 1 year with licence, accident risk in terms of accidents per 10 million $\mathrm{km}$ was found to be reduced among those who utilised the reform. The reduction was approximately $35 \%$.

The aim of the process evaluation was to analyse how the new age limit was used and by whom. The results of the process evaluation, based on data from the national licence register, show that $45-50 \%$ of the 16 years old population did make use of the new possibilities during the first $2 \frac{1}{2}$ years after the introduction by applying for and receiving a learner's permit. From logbooks, filled out by randomly drawn samples of learner drivers, it was also found that $95 \%$ of the youngsters with a low-age learner's permit actually did practice. The total amount of practising was also measured through questionnaires distributed to randomly drawn samples of drivers. The results from these showed an increase in the amount of practice before licence to $117.6 \mathrm{~h}$ (mean). This was an increase with approximately 2.5 times compared to young learner drivers before the change (mean $=47.6 \mathrm{~h}$ ) and three times compared to those who started at $17 \frac{1}{2}$ years of age after the change $($ mean $=41.4 \mathrm{~h}$ ).

An analysis of the accident involvement during practising showed that the accident risk (per hour and per

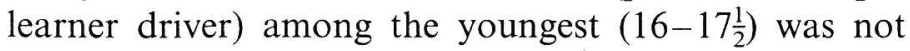
higher than in the older group $\left(17 \frac{1}{2}-18\right)$. This suggests that during the after-reform-period, the increased practising at a lower age was not more dangerous than whatever education given during the pre-reform period. Calculated as accidents per driver the accident involvement was approximately 35 times higher during the first 2 years after licensing than during the 2 years of practising. Comparable data on exposure have not been available but these per driver figures give a general public health perspective of the situation.

One of the most well known trials with extended formal education and training for learner drivers was the DeKalb project. The DeKalb education comprised $72 \mathrm{~h}$ divided into $32 \mathrm{~h}$ of class room education, $16 \mathrm{~h}$ of simulator driving, $16 \mathrm{~h}$ of driving range training, $3.5 \mathrm{~h}$ of training on evasive manoeuvres and $5 \mathrm{~h}$ of on-street training. In a review of the large number of evaluations of the program, Mayhew and Simpson (1996) concluded that despite significant efforts, the DeKalb evaluation failed to provide evidence of the beneficial effects of formal instruction. The project is sometimes looked upon as an effort to increase the experience as a driver. The problem is, however, that very little of the time was spent in actual traffic. Even if all the real driving is taken into account in the DeKalb study, the amount of true driving will only sum up to $25 \mathrm{~h}$. This may be compared to the normal Swedish learner driver who before the lowering of the age limit was practising in real traffic situations for approximately $48 \mathrm{~h}$ on average (Gregersen, 1996b). Yet another problem found in the DeKalb study was that the participants tended to get their licence earlier and thus were more exposed.

The second variant of training with extended experience is the staged process, known as graduated licensing. This is a system whereby the student goes through several stages, at each of which the degree of difficulty and the driver's responsibility are increased gradually. It is possible, for instance, to control where, when and how to practice in the various stages. It is also possible to integrate limitations such as driving on the motorway, during the hours of darkness, above a certain speed or with even lower blood-alcohol levels. Several evaluations of graduated licensing systems have been undertaken around the world, with promising results. This is the case in New Zealand (Langley et al., 1996) where the reduction of accidents was estimated to 7$23 \%$ depending on the influence of exposure, and in Ontario (Boase and Tasca, 1998) where the reduction was $31 \%$. Several reports have been published where more recent experiences from graduated licensing are presented (Haworth, 1994; Smith, 1994; Langley et al., 1996; Mayhew and Simpson, 1996; Simpson, 1996; TRB, 1996).

\section{Aim}

The aim of this study was to evaluate the effects of the reform of a lowered age limit for practising car driving in terms of accident involvement (accidents per 1000 licence holders and accidents per 10 million $\mathrm{km}$ ) during the first 2 years after licensing among young novice drivers. Two hypotheses have been tested. The first was that those who utilised the new age limit will have lower accident involvement as novice drivers compared to young drivers who did not utilise the prolonged practising period before or after the change. The 
second hypothesis was that accident involvement among the youngest, novice drivers in general would be reduced as an effect of the reform.

\section{Materials and methods}

\subsection{Evaluation design}

The change of age limit was introduced on a national level which made it impossible do evaluate the change with an experimental design. It was, however, decided that an evaluation was important so another design had to be chosen. Two designs were discussed, one was a before-after comparison and the second a comparison between those who after the change made use of the lowered age limit and those who did not. Both the designs have disadvantages. The before-after design cannot differentiate effects of the change from other time-related changes such as economical changes in society, unemployment or changes in weather conditions from one year to another. The second comparison between the users and the non-users includes a self-selection bias of for example greater interest or resources among the users.

In order to minimise these problems as much as possible without having the possibility to carry out an experiment, the two designs were combined. Three groups were thus compared as shown in Fig. 1. To control for the trends over time, and thereby avoid some of the problems in the before-after comparison, an analysis of the accident involvement trend among young drivers over the period 1992-1997, the period covered in the evaluation, was performed.

Three comparison groups have thus been used in the present study. The group, which has made use of the possibilities to start practising at 16 will in this presentation, be referred to as the 16 years group. For one of the two control groups, driver licence was obtained during the pre-reform period, before the change. These will be referred to as the old $17 \frac{1}{2}$ years group. The second control group, which comprise youngsters who, after the reform, did not make use of the extended training period but started practising after $17 \frac{1}{2}$ :, will be referred to as the new $17 \frac{1}{2}$ years group. Common for all groups was that the age limit for getting a licence was 18 years.

\subsection{Confounding factors}

In addition to the trend analysis, two other possible confounding factors have been estimated. These are socio-economic background differences and age at which the drivers got their licence. In accordance with earlier research (Jessor, 1988; Beirness and Simpson, 1991; Berg, 1994; Murray, 1998) it may be assumed that people with different socio-economic background also have different probabilities of accident involvement. Consequently, parts of the difference in accident involvement between the groups may be explained by differences in such background factors. Detailed results on these differences among the learner drivers in the three comparison groups have been published earlier (Gregersen, 1996b). From these results the answers of one of the questions in the questionnaire, 'What is the highest education in your family?' has been used as an indicator of their socio-economic status. It has not been possible to apply any exact level of this influence on accident involvement since such data were not available. A generous interpretation of this influence was used in order to avoid overestimation of the effect of the change of age limit.

The accident involvement may also be influenced by the age at which the drivers are licensed. If the 16 years drivers are licensed earlier, their accident involvement may partly be caused by their earlier exposure to traffic. This must also be regarded as a result of the change of age limit and the effects must thus be corrected correspondingly. This problem has been shown in the evaluations of the DeKalb project (Mayhew and Simpson, 1996). In that study it was found that the drivers who received the full training programme were licensed earlier than the control group.

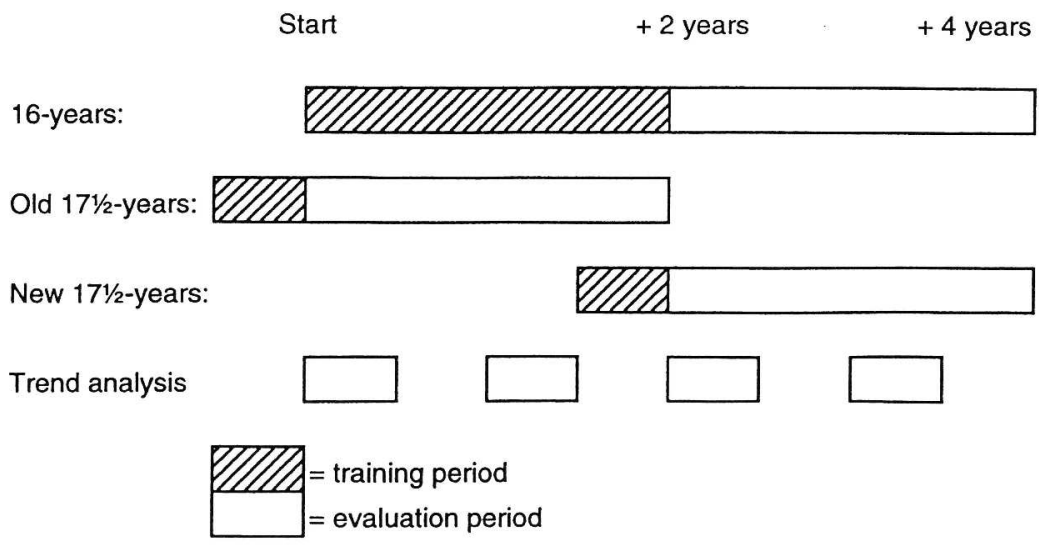

Fig. 1. Design of the evaluation of the 16 years age limit for practising. 


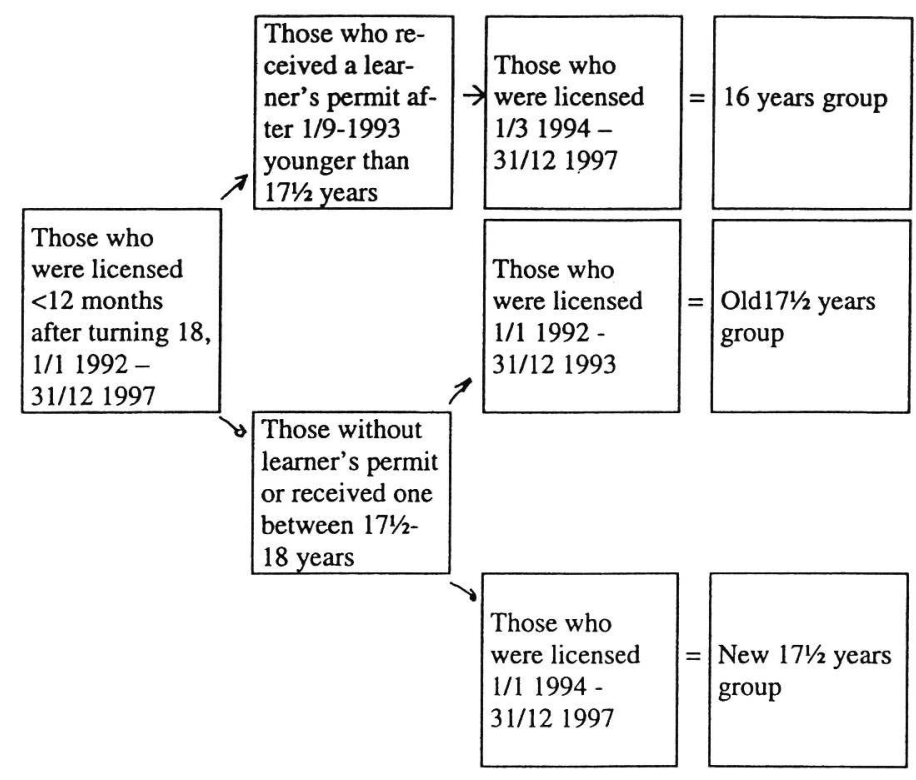

Fig. 2. Criteria for defining the three comparison groups in the national licence register and the police records.

\subsection{Population register data}

Information about accidents was collected from the register of police reported accidents. Only the accidents causing fatalities or personal injuries were used. For each accident involved driver, type and date of accident were obtained from the register. Information on date of learner's permit and licence were obtained from the national register on licences. The criteria for assigning the drivers to each of the three comparison groups are shown in Fig. 2. The first common criterion was that the licensing age should be under 19 years. The second criterion was that the selected drivers should have held their licence for more than 2 years since the aim was to present the effect over the first 2 years with a licence. The analyses are based on all Swedish drivers who fit into these criteria over the period from January 1st 1992 to December 31st 1997. In total the analyses concern 243823 drivers and 4192 police reported accidents.

In the additional trend analysis the samples included young drivers between 20 and 24 years. Still younger drivers were excluded to obtain comparison data, which were independent from reform effects.

Table 1

Sample size, response rate and effective group size in the questionnaire study

\begin{tabular}{|c|c|c|c|}
\hline Group & Sample size & $\begin{array}{l}\text { Effective group } \\
\text { size }\end{array}$ & $\begin{array}{l}\text { Response rate } \\
(\%)\end{array}$ \\
\hline Old $17 \frac{1}{2}$ years & 1200 & 1011 & 84.3 \\
\hline $\begin{array}{l}\text { New } 17 \frac{1}{2} \text { years } \\
16 \text { years }\end{array}$ & 2000 & $\begin{array}{r}422 \\
1024\end{array}$ & $\begin{array}{l}72.2 \\
72.2\end{array}$ \\
\hline
\end{tabular}

\subsection{Questionnaires}

The samples used for the questionnaire study were randomly drawn from the Swedish national licence register. The questionnaires were mailed to drivers in the three comparison groups who had been licensed for 2 years. Due to the fact that the drivers in the old $17 \frac{1}{2}$ years group by definition were licensed earlier than the other groups, they received their questionnaires 1 year before the other groups (see Fig. 1). The sample sizes were 1200 in the old $17 \frac{1}{2}$ years group and altogether 2000 in the remaining groups. Drivers in this sample were assigned 16 years drivers or new $17 \frac{1}{2}$ years drivers in accordance with their answer to a question about their age when they started practising. Two reminders were used, the first after 3 weeks and the second after another two weeks. The response rates were $84 \%$ in the sample of 1200 and $72 \%$ in the sample of 2000 . The final group sizes are shown in Table 1.

In this presentation, only two types of data from the questionnaires have been used. These are data on mileage and socio-economic background. Other results of the questionnaire studies have been published earlier by Gregersen (1996b, 1997).

\subsection{Analysis procedure}

1. The three comparison groups were identified in the two population registers, that is, the total number of drivers in each group and, the number of drivers in each group who had been involved in police reported accidents with personal injuries.

2. Individual data about date and age of learner's permit and licence were transferred from the licence register to the corresponding post in the accident register. The Swedish individual social security number was used to match individuals in the two registers.

3. The accidents per 1000 licence holders in each comparison group were calculated.

4. Data on mileage driven in each group obtained from the questionnaires were used as estimates of exposure, to be used in the calculations of risk from the population registers data.

5. Accident risk (accidents per 10 million $\mathrm{km}$ ) was calculated for each of the three comparison groups.

6. The general effect of the reform was analysed by combining the 16 years drivers and new $17 \frac{1}{2}$ years drivers and comparing their accident involvement with the old $17 \frac{1}{2}$ years drivers.

7. The accident involvement of the 16 years drivers, the new $17 \frac{1}{2}$ years drivers and the old $17 \frac{1}{2}$ years drivers were compared to each other.

8. Questionnaire data on socio-economic background, trends in national accident statistics and national register data on differences in licensing age were used to estimate confounding factors. 


\subsection{Statistical methods}

Differences in accident risk were estimated using the incidence density ratio (IDR) with $95 \%$ confidence intervals (McNeil, 1996).

\section{Results}

\subsection{Effect of the reform}

Table 2 shows the accident involvement of each of the three comparison groups and the corresponding aggregated measure of accident involvement of the 16 years and the new $17 \frac{1}{2}$ years groups. A comparison of the accident involvement between the old $17 \frac{1}{2}$ years group and the combined figures from the other groups (the 16 years and new $17 \frac{1}{2}$ years groups) gives a measure of the general effect of the reform. The analysis shows that the reduction of accidents per 1000 drivers after the reform compared to before was $20.8 \%$ and the reduction in accidents per 10 million $\mathrm{km}$ was $17.2 \%$.

Each of the three comparison groups was compared as well. The results show that the 16 years group had a lower number of accidents per 1000 licence holders and a lower accident risk (accidents per 10 million $\mathrm{km}$ ) compared to each of the two control groups. The difference in accident risk between the 16 years group and the two control groups were in both cases $45.9 \%$. All differences except between the two $17 \frac{1}{2}$-year groups were significant $(P<0.05)$ as shown in Table 3.

Table 3 shows the IDR estimates and the $95 \%$ confidence intervals concerning differences in accident involvement per person-kilometres. These calculations have been used in the tests of the hypotheses defined for the study (see the aim section above). The results support both hypotheses; a lowered accident involvement among those who have utilised the reform and, a positive general safety promoting effect of the reform.

In Fig. 3, the monthly development of accident involvement per 1000 licence holders is shown. As shown in Fig. 3, the 16 years group has a lower accident involvement all through the 2 years period. Still after 24 months there are clear differences between the 16 years group and the two control groups.

\subsection{Gender differences}

The relative distribution of accidents per 1000 licence holders for men and women is similar in the three comparison groups. In all groups men are involved in approximately $75 \%$ of the accidents. Accident risk, expressed as accidents per 10 million $\mathrm{km}$, was found to be reduced after the reform among men as well as women, but the reduction was higher for women (Table 4).

Table 5 shows the IDR estimates for men and women separately. The same comparisons were made as for the whole groups in Table 3. The results support both hypotheses also when they are applied to each of the genders separately.

\subsection{Confounding factors}

The influence of three additional possible confounding factors was estimated in this evaluation. These were socio-economic background, general accident trend and

Table 2

The accident involvement the first 2 years with a licence in the three comparison groups of the evaluation and before-after the change

\begin{tabular}{|c|c|c|c|c|c|}
\hline Group & $\begin{array}{l}\text { Number of } \\
\text { accidents }\end{array}$ & $\begin{array}{l}\text { Number of } \\
\text { drivers }\end{array}$ & $\begin{array}{l}\text { Accidents per } 1000 \\
\text { drivers }\end{array}$ & Mileage $(\mathrm{km})^{\mathrm{a}}$ & Accidents per 10 million $\mathrm{km}^{\mathrm{a}}$ \\
\hline $\begin{array}{l}\text { Old } 17 \frac{1}{2} \text { years } \\
\text { (before) }\end{array}$ & 2000 & 102302 & 19.55 & 20060 & 9.75 \\
\hline New $17 \frac{1}{2}$ years & 1665 & 89507 & 18.60 & 19140 & 9.72 \\
\hline 16 years & 527 & 52014 & 10.13 & 19240 & 5.27 \\
\hline New $17 \frac{1}{2}+16$ (after) & 2192 & 141521 & 15.49 & 19180 & 8.07 \\
\hline
\end{tabular}

a Mileage estimated from questionnaire data.

Table 3

Incidence density ratio (IDR) estimates and 95\% confidence intervals concerning differences in accident involvement per person-kilometres the first 2 years with a licence

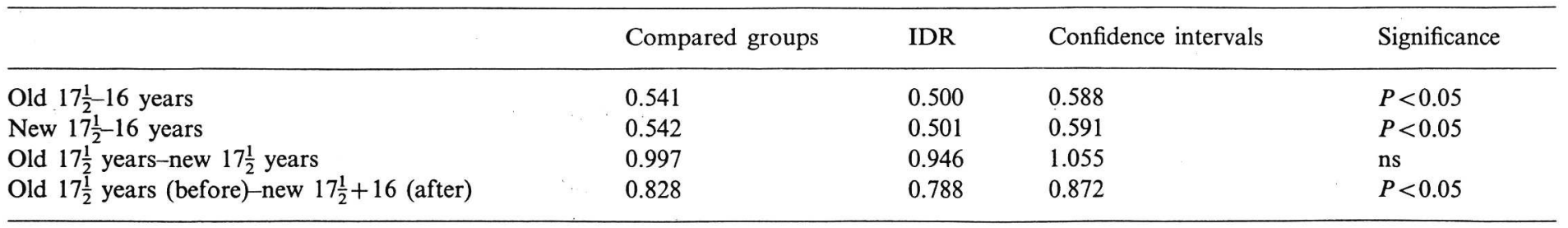



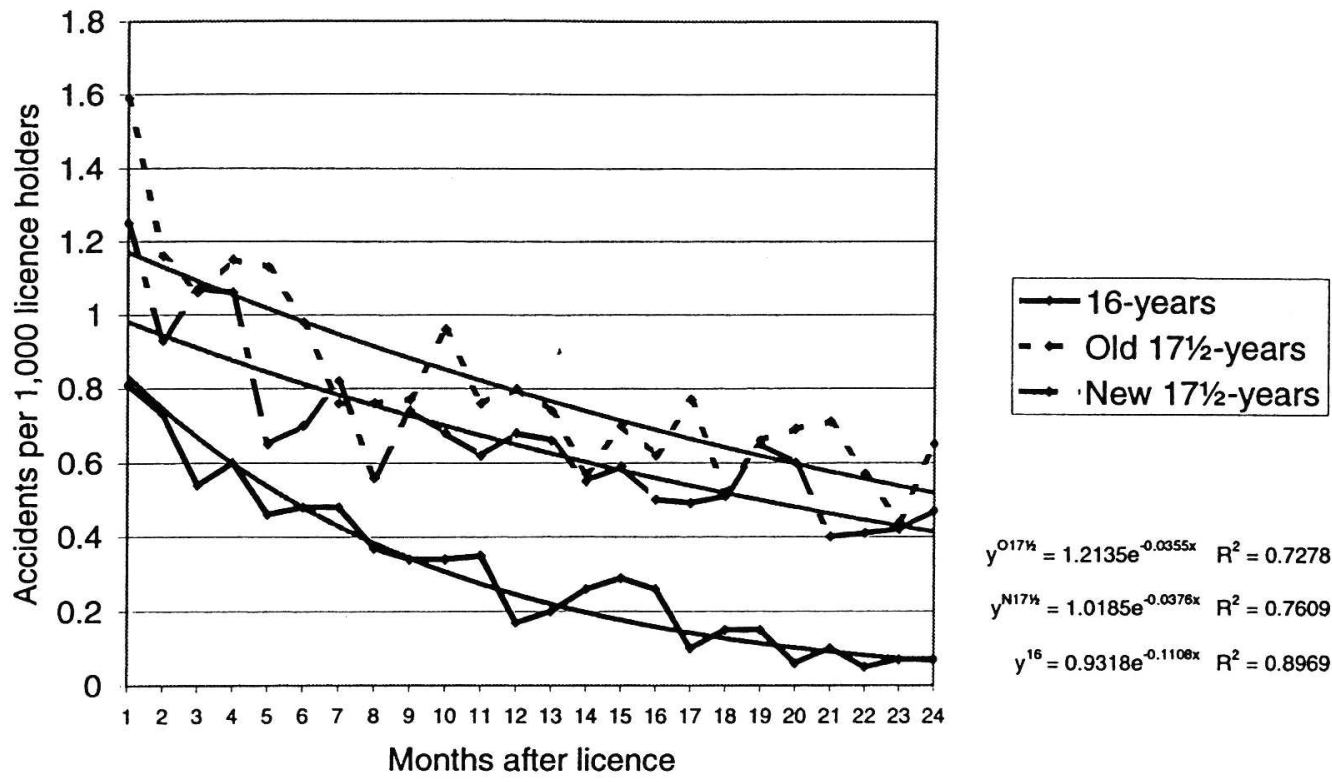

$y^{0.17 k}=1.2135 e^{-0.0355 \times} \quad R^{2}=0.7278$

$y^{N 17 k}=1.0185 e^{-0.0978 x} R^{2}=0.7609$

$y^{16}=0.9318 e^{-0.1108 x} R^{2}=0.8969$

Fig. 3. Police reported accidents per 1000 licence holders during the first 24 months with a licence in the three comparison groups.

Table 4

Accident involvement among men and women in the three comparison groups

\begin{tabular}{lccr}
\hline Group & Accidents per 1000 licence holders & Mileage $^{\mathrm{a}}$ & ${\text { Accidents per } 10 \mathrm{million}^{\mathrm{k}} \mathrm{km}^{\mathrm{a}}}$ \\
\hline Old $17 \frac{1}{2}$ years, men & 25.08 & 24683 & 10.16 \\
Old $17 \frac{1}{2}$ years, women & 11.88 & 14673 & 8.09 \\
New $17 \frac{1}{2}$ years, men & 24.48 & 24424 & 10.02 \\
New $17 \frac{1}{2}$ years, women & 10.95 & 13071 & 8.38 \\
16 years, men & 13.92 & 24780 & 5.62 \\
16 years, women & 5.32 & 12916 & 4.12 \\
\hline
\end{tabular}

${ }^{\text {a }}$ Mileage estimated from questionnaire data.

Table 5

Incidence density ratio (IDR) estimates and $95 \%$ confidence intervals concerning differences in accident involvement per person-kilometres the first 2 years with a licence (men and women)

\begin{tabular}{|c|c|c|c|c|}
\hline & IDR & \multicolumn{2}{|c|}{ Confidence intervals } & Significance \\
\hline \multicolumn{5}{|l|}{ Compared groups, men } \\
\hline Old $17 \frac{1}{2}$ years -16 years & 0.553 & 0.498 & 0.621 & $P<0.05$ \\
\hline Old $17 \frac{1}{2}$ years-new $17 \frac{1}{2}$ years & 0.986 & 0.917 & 1.067 & ns \\
\hline Old $17 \frac{1}{2}$ years(before)-new $17 \frac{1}{2}+16$ (after) & 0.827 & 0.773 & 0.889 & $P<0.05$ \\
\hline \multicolumn{5}{|l|}{ Compared groups, women } \\
\hline Old $17 \frac{1}{2}$ years-new $17 \frac{1}{2}$ years & 1.035 & 0.917 & 1.188 & ns \\
\hline Old $17 \frac{1}{2}$ years(before)-new $17 \frac{1}{2}+16$ (after) & 0.841 & 0.751 & 0.957 & $P<0.05$ \\
\hline
\end{tabular}

licensing age. The aggregated results of these estimations are presented in Table 8.

\subsection{Socio-economic preconditions}

In the results of the questionnaire study (Gregersen, 1996b) it was found that the socio-economic preconditions differ between the groups which in itself may cause differences in accident involvement. The result of the question 'What is the highest education in your family?' is presented in Fig. 4. The results show that a higher percentage of the 16 years group belongs to families with university education compared to the other groups. These results are representative for the distribution of other background data published earlier by Gregersen (1996b). 
A generous interpretation of the influence of these background preconditions was applied on the results of the present study in order to avoid overestimation of the effect of the reform. Based on the results shown in Fig. 4 the differences in socio-economic preconditions in the 16 years group was approximated to $7.8 \%$ compared to the old $17 \frac{1}{2}$ years group and $21.9 \%$ compared to new $17 \frac{1}{2}$ years group. With an extreme and generous assumption, that the over-represented share of the drivers with higher level of education in the family have no accidents at all, the accident involvement of the 16 years group would be reduced with 7.8 and $21.9 \%$, respectively in the comparison with each of the control groups. The calculations follow the formula

$1-(a /(b-x \%$ of $b)$

where $a$ is the lowest risk value and $b$ is the highest as presented in Table 2. $x$ is one of the 7.8 or 21.9 , which were explained above.

\subsection{General accident trend}

A comparison of the accident involvement between the 16 years and the old $17 \frac{1}{2}$ years groups may also, over and above any effect of the reform, suffer from effects of changes in the general year-to-year trend of accidents as data were obtained at different time periods. In order to control for this, a trend analysis of accident involvement was carried out among drivers 20-24 years of age during the period of the evaluation study. In Table 6 data from the national statistics of accident involvement show that the number of accidents per 1000 licence holders was almost exactly the same over the entire evaluation period. There was a reduction from 1992 to 1993 which only influences the very first drivers of the old $17 \frac{1}{2}$ years group itself since the follow-up period of the old $17 \frac{1}{2}$ years drivers includes the years 1992-1995. The mean of accidents per 1000 licence holders over these years was 5.95. This can be compared to the mean level of 5.8 accidents per 1000 licence holders for the follow-up period of the 16 years and the new $17 \frac{1}{2}$ years drivers, which include the period from 1994 to 1997 . The difference and the trend related reduction is thus $1-(5.8 / 5.95)=2.5 \%$. For the calculations of how these $2.5 \%$ influences the difference between the groups, $x$ in the formula above has been replaced with 2.5 and $b$ with the result of the previous calculation of $(b-x \%$ of $b)$ in the formula.

\subsection{Licensing age}

In a comparison of licensure age it was found that the 16 years group was licensed approximately 1 month earlier than the new $17 \frac{1}{2}$ years and almost at the same age as the old $17 \frac{1}{2}$ years group (Table 7 ).

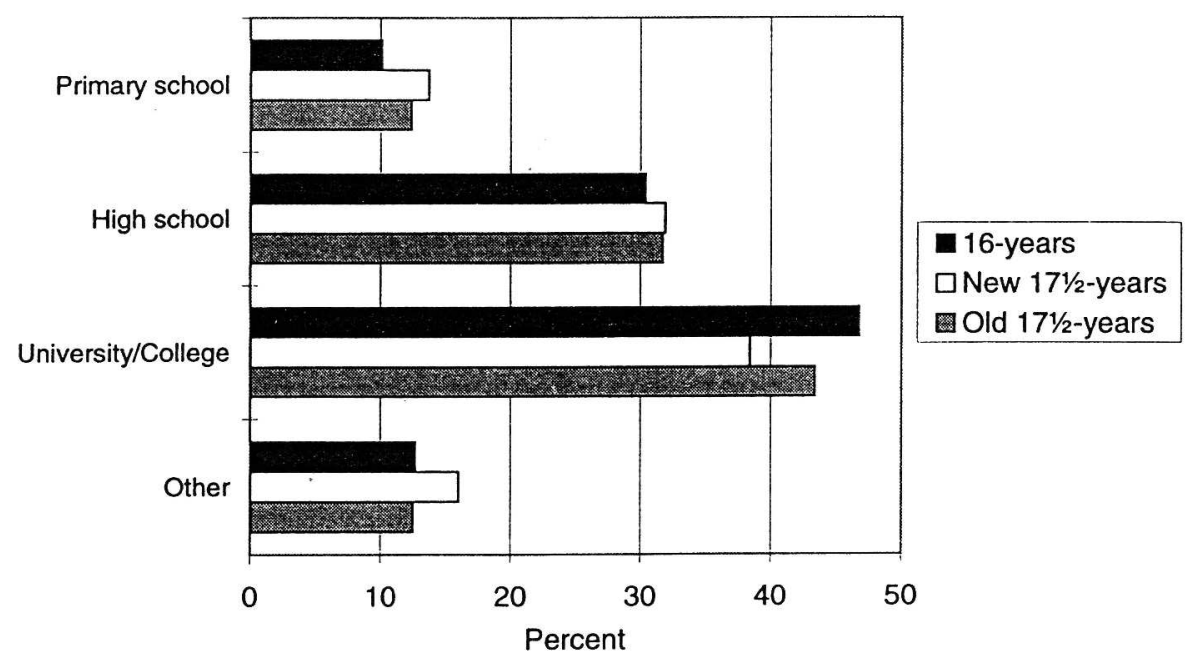

Fig. 4. Distribution of highest education in family in the three comparison groups.

Table 6

Drivers 20-24 years old involved in accidents during the years 1993-1996 (1997 not available)

\begin{tabular}{llll}
\hline Year & Accidents per 1000 licence holders & Drivers involved in accidents & Licence holders \\
\hline 1992 & 2925 & 452000 & 6.5 \\
1993 & 2488 & 439000 & 5.7 \\
1994 & 2523 & 433000 & 5.8 \\
1995 & 2444 & 422000 & 5.8 \\
1996 & 2352 & 405000 & 5.8 \\
\hline
\end{tabular}




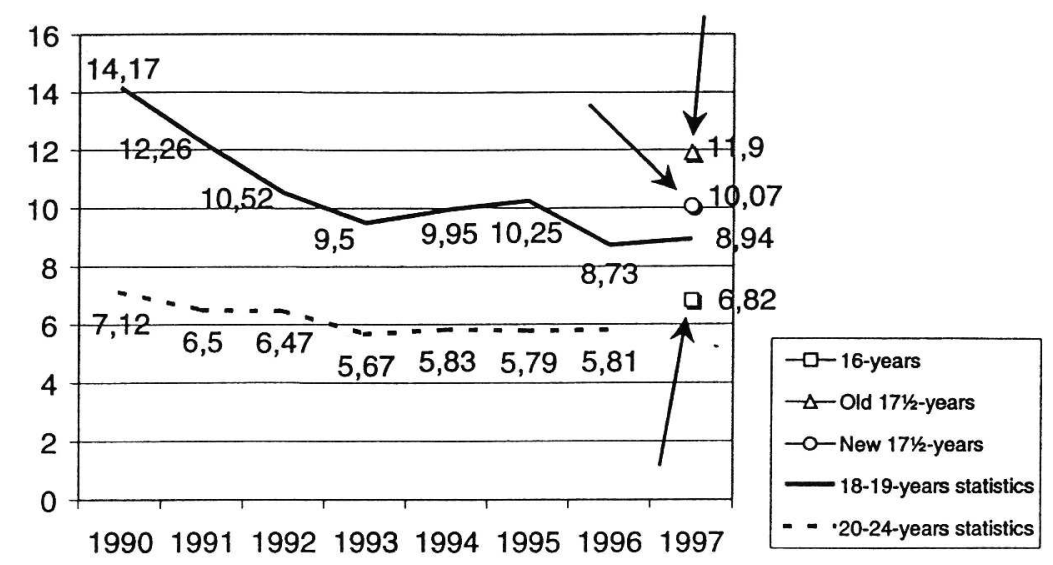

Fig. 5. Accidents per 1000 drivers among young drivers in national Swedish statistics 1990-1997 compared with the evaluation results.

Table 7

Mean of licensure age in the three comparison groups

\begin{tabular}{|c|c|c|c|}
\hline & Old $17 \frac{1}{2}$ years & New $17 \frac{1}{2}$ years & 16 years \\
\hline Mean age & 18.31 & 18.40 & 18.32 \\
\hline
\end{tabular}

After compensating the new $17 \frac{1}{2}$ years drivers for this one month lack of extra exposure, which is approximately $4.2 \%$ of 24 months (used as $x$ in the formula above), together with the estimated influence of the other two confounding factors, the total effect of the extended learning period was estimated to approximately $15 \%$ calculated as accidents per 10 million $\mathrm{km}$. The resulting difference in accident risk for those who have utilised the lowered age limit was approximately $40 \%$ compared to old $17 \frac{1}{2}$ years drivers and $24 \%$ compared to new $17 \frac{1}{2}$ years drivers (Table 8 ). The reason why the difference between the risks of the 16 years group and the new $17 \frac{1}{2}$ years group has decreased so much, from 45.8 to $23.9 \%$, is mostly because the estimated difference in socio-economic background is as large as $21.9 \%$.

The initial differences before the compensation of confounding factors in Table 8 is based on register and exposure data solely and have been calculated with the formula $1-(a / b)$

where $a$ is the lowest risk value and $b$ the highest as presented in Table 2.

Since the calculations are based on national figures, but on drivers with at least 2 years with a licence, the results should expectedly be visualised in the development of accident involvement in the general statistics on all novice drivers in the same age group, 18-19 years old. Fig. 5 shows the development of accidents per 1000 licence holders 1990-1997 and the corresponding results from Table 2 , recalculated to give annual accident involvement figures. It is evident from Fig. 5 that the correspondence supports the validity of the evaluation results. When the first drivers with a full 2-year training period have been licensed, which is in September 1995, the accident involvement is reduced with approximately $15 \%$. The outcome is not exactly the same in the evaluation and in the national statistics, but that should not be expected since the groups in the evaluation and in the national statistics are not defined in the same way.

\section{Discussion}

The results of this study show that a driver training reform implemented in Sweden in 1993, which implied

Table 8

Estimated influence of confounding factors on the comparisons performed in the evaluation

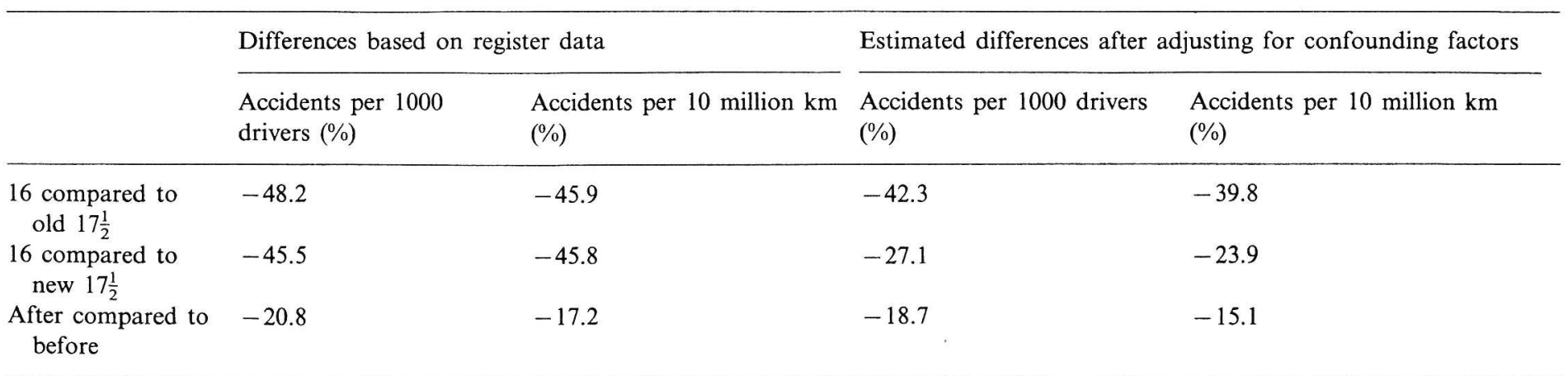


a prolonged driver training period, has had a general accident risk reducing effect on young novice drivers with approximately $15 \%$ during a follow-up period of 2 years. Drivers who actively engaged in the prolonged training were shown to benefit from the reform whereas those who did not use the longer driver training period did not benefit. Compared to a pre-reform period, the accident reduction after the reform was approximately $40 \%$ for those who utilised the extended training period.

The estimations of the effects of the reform have taken some confounding factors into account. The influence of three confounding factors, over and above that of exposure, have been approximated. These are, however, crude approximations and there may still be other confounding factors not controlled for. There may for example be unmeasured motivational aspects that influence the willingness to start practising early. It can, however, be concluded that the reform has given young drivers the opportunity to gain more experience. Some youngsters have utilised this opportunity and others have not. The total effect of the reform, including the existing distribution of different motivation to participate, is shown in the results obtained in this evaluation. A deeper analysis of motivational factors would not have changed the results concerning the total reform effect but it may have helped to understand the causal relations between for example experience and accident risk better.

It would also, in order to increase this understanding, have been interesting to relate accident involvement directly to socio-economic background, attitudes, selfassessment, self reported driving style etc. in a regression analysis or in a chaid analysis. This has, however, not been possible since data has been collected from different sources. Accident information was collected from national registers and all the other information comes from questionnaires among random samples of licence holders. Comparisons between these two sources were possible on an aggregated group level only.

One of the confoundings that was controlled for was the general accident trend among young drivers. In this trend analysis drivers between 20-24 years were used. The slightly older age group was chosen because influence from the reform effect should be avoided. This difference in age may, however, result in an underestimation of the trend. The younger age groups may have been more sensitive to general trends in society such as economy and unemployment and therefore bias the trend estimate performed here. It is, however, not possible to distinguish such trends from the trends caused by the 16-years reform among the youngest drivers since they apply to the same group.

Since the purpose of the reform was to give the learner driver an opportunity to acquire experience, the results must be interpreted in relation to the amount of practice acquired. Just the possibility to start at an early age does not necessarily make all learner drivers practice as much as possible. Earlier results (Gregersen, 1996b) have shown that the amount of practising was 2.5-3 times higher in the 16 years group compared to the control groups. It would have been of highest interest to do direct analyses of the correlation between amount of practising and accident involvement. This was, however, not possible since accident and exposure data were collected from different sources. Comparisons were only possible at an aggregated level.

The findings support the theory of skill acquisition (Rasmussen, 1984). Regarded in the perspective of Rasmussen's theory, skill acquisition takes place purely as a development from conscious decision-making and reflection towards gradually increasing automation. In this process, systems of behavioural rules and mental models are created so that car driving, to a greater extent can take place with but occasional mental effort. Such sequences can be expected as a result of increased exposure to a variety of traffic situations in which the student builds up a bank of routine and recognition.

Although the accident reduction in the 16 years group was approximately $40 \%$, the general reform effect was $15 \%$. The obvious reason for this difference was apparently that only a part of the young learner drivers made use of the lowered age limit. If a larger part of the young learner driver population can be persuaded to start early and to practice more, the safety potential of the lowered age limit may be exploited even more. As shown in many different studies (e.g. Gregersen, 1996a; Simpson, 1996), there are, however, also a large number of other factors that are related to driver behaviour and accident involvement of young, novice drivers. Many of these factors cannot be reached through increased experience solely.

With the results obtained, there is thus a sound basis for continued development of driver training towards a higher safety or what in Sweden is proclaimed by the parliament as the Vision Zero, which is a strategy towards zero killed or severely injured road users. The main emphasis in the Vision Zero is on injury prevention through measures in the vehicle and in the road environment. A philosophy behind these efforts is that people normally make mistakes, also in traffic and also unintentionally. If such mistakes are made, for example among young, novice drivers, the environment should be forgiving in order to prevent serious consequences. Behaviourally oriented measures aiming at reducing such mistakes are, however, also important in the Vision Zero, such as improvement of speed adjustment and driver education. This means, in addition to other types of road safety measures, for example further streamlining of the learning and experience-accumulation process. It is also a matter of reducing the number of accidents during driver training; individualising 
driver training in order to increase risk awareness; reducing young male's overestimation of their driving skill; conveying an insight about the influence of group pressure, lifestyle and personality on driving style and accident involvement; and through all this, stimulate motivation to drive carefully and with greater safety margins. For many of these measures, the process of development has been going on for a long period of time in many countries. In Sweden, the government and the Swedish National Road Administration have decided to continue the development of driver education. By making use of the frontline of knowledge about young and novice drivers, a graduated education system is currently being developed. The most important aim of this work is to reduce accident involvement among novice drivers even further.

\section{Acknowledgements}

The evaluation study has been carried out on commission from the Swedish National Road Administration.

\section{References}

Beirness, P.J., Simpson, H.M., 1991. Predicting Young Driver Crush Involvement. The Role of Lifestyle Factors. International Symposium New to the Road, Prevention Measures for Young and Novice Drivers. Halifax, Canada.

Berg, H.Y., 1994. Lifestyle, Traffic and Young Drivers-An Interview Study. VTI Report 389A. Swedish Road and Transport Research Institute, Linköping, Sweden.

Boase, P., Tasca, L., 1998. Graduated licensing system evaluation. Interim report 198. Safety Policy Branch, Ministry of Transportation of Ontario, Canada.

Cavallo, A., Triggs, T.J., 1996. Young Driver Research Strategy. Report No. 85. Monash University, Clayton, Victoria.

Cooper, P.J., Pinili, M., Chen, W., 1995. An examination of the crash involvement rates of novice drivers aged 16 to 55. Accid. Anal. Prev. 27, 89-104.

Drummond, A.E., Triggs, T.J, Macdonald, A.W., Bowland, L., 1993. Young Driver Research Program: Overview Report. Report No. CR 121. Monash University, Clayton, Victoria.

Fafet, H., 1990. Experiences from the 16-years age limit in France. Presentation organised by the Committee for Driver's Licence 2000. Stockholm, Sweden.

Gregersen, N.P., 1996a. Young Car Drivers. Why Are They OverRepresented in Traffic Accidents? How Can Driver Training Improve Their Situation? VTI Report 409A. Swedish Road and Transport Research Institute, Linköping, Sweden.
Gregersen, N.P., 1996b. Evaluation of 16-Years Age Limit For Driver Training-First Report. VTI Report 418A. Swedish Road and Transport Research Institute, Linköping, Sweden.

Gregersen, N.P., 1997. Practising from the age of 16, some evaluation results from Swedish driver training. In: Rothengatter, T., Carbonell Vaya, E. (Eds.), Traffic and Transport Psychology, Theory and Application. Pergamon, Amsterdam, pp. 423-430.

Haworth, N., 1994. Young driver research program: evaluation of Australian Graduated Licensing Scheme. Report CR136. Federal Office of Road Safety, Canberra, Australia.

Jessor, R., 1988. Risky driving and adolescent problem behavior: an extension of the problem-behavior theory. Alcohol Drugs Driv. 3, $3-4$.

Langley, J.D., Wagenaar, A.C., Begg, D.J., 1996. An evaluation of the New Zealand graduated driver licensing system. Accid. Anal. Prev. 28, 139-146.

Levy, D.T., 1990. Youth and traffic safety: the effects of driving age, experience, and education. Accid. Anal. Prev. 22, 327-334.

Lynam, D., Twisk, D., 1995. Car Driver Training and Licensing Systems in Europe. TRL Report No. 147. Transport Research Laboratory, Crowthorne, UK.

McNeil, D., 1996. Epidemiological Research Methods. Wiley, Chichester, UK.

Maycock, G., Lockwood, C.R. and Lester, J.F., 1991. The Accident Liability of Car Drivers. TRL Research Report 315. Transport Research Laboratory, Crowthorne, UK.

Mayhew, D.R., Simpson, H.M., 1996. Effectiveness and Role of Driver Education and Training in a Graduated Licensing System. The Traffic Injury Research Foundation of Canada, Ottawa, Canada.

Moe, D., 1992. Føreropplæring klasse B for 16 årillger. (Driver Education for 16-Years Old Learner Drivers). SINTEF Rapport STF63 A92002. SINTEF Samferselsteknikk, Trondheim, Norway. (In Norwegian.)

Murray, A., 1998. The home and school background of young drivers involved in traffic accidents. Accid. Anal. Prev. 30, 169-182.

Page, Y., 1995. Jeunes conducteurs, apprentissage anticipé de la conduite et accidents de la route. Cah. Obs. 2, 15-55.

Pelz, D.C., Schuman, S.H., 1971. Drinking, Hostility and Alienation in Driving Of Young Men. Paper presented at the 3rd Annual Alcohol Conference, Washington, DC.

Rasmussen, J., 1984. Information Processing and Human-Machine Interaction. An Approach to Cognitive Engineering. North-Holland, New York.

Simpson, H. (Ed.), 1996. New to the Road. Reducing the Risks for Young Motorists. Youth Enhancement Service, University of California, LA.

Smith, M.F., 1994. Research Agenda for an Improved Novice Driver Education Program. Report to the Congress. NHTSA Report DOT HS 808 161. National Highway Traffic Safety Administration, Washington DC.

Spolander, K., 1983. Bilforares olycksrisker. En modell testad pa man och kvinnor. (Accident risks among drivers. A model tested on men and women). VTI Report 268. Swedish National Road and Transport Research Institute, Linköping, Sweden. (In Swedish.)

TRB, 1996. Graduated Licensing: Past Experience and Future Status. Transportation Research Circular 458. Transportation Research Board, Washington, DC. 
VI FORSKAR FÖR ETT LIV I RÖRELSE

Statens väg- och transportforskningsinstitut (VTI) har kompetens och laboratorier för kvalificerade forskningsuppdrag inom transporter och samhällsekonomi, trafiksäkerhet, fordon, miljö samt för byggande, drift och underhăll av vägar och järnvägar.

The Swedish National Road and Transport Research Institute (VTI) has laboratories and know-how for advanced research commissions in transport and welfare economics, road safety, vehicles and the environment. It also has research capabilities for the construction, operation and maintenance of roads and railways.

\section{Adress}

Postal address

SE-581 95 Linköping, Sweden
Telefon

Telephone

Nat 013-20 4000

Int +4613204000
Fax

E-post

E-mail

Nat 013-14 1436

Int +4613141436 